RB, Bigal ME, Diamond $\mathrm{M}$ et al; on behalf of the AMPP Advisory Group. Migraine prevalence, disease burden, and the need for preventive therapy. Neurology Jan 30, 2007;68;343-349). (Reprints: Dr Richard B Lipton, The Albert Einstein College of Medicine, 1300 Morris Park Ave, Bronx, NY, 10461).

COMMENT. Criteria for preventive treatment recommended as a benchmark by an expert panel are based on the headache frequency and degree of impairment. If headaches occur more than 2 days per month and result in severe impairment, or more than 3 days with some impairment, treatment should be offered. The authors stress, however, that in practice, the decision to treat is dependent on several factors. The study shows that migraine preventive therapy is underutilized. Whereas $39 \%$ of patients meet criteria for offering or considering preventive medication, only $12 \%$ of those responding to this survey currently receive it.

Lack of proven efficacy reported by a panel of experts is one plausible reason for the under use of preventive medications in migraine. Of 12 agents reviewed by Committees of the Child Neurology Society and AAN, only one, the calcium channel blocker, flunarizine, which is unavailable in the US, has shown significant benefit in double-blind, placebocontrolled, crossover trial. Trials of antiepileptic medications, antidepressants, antihistamines, and antihypertensive agents have provided insufficient data, conflicting results, or have failed to demonstrate any effect (Lewis D et al. Neurology 2004;63:22152224). Perhaps the criteria employed by this panel of neurologists were too stringent. A more promising assessment of the effectiveness of propranolol, amitryptyline, and antiepileptic medications is provided by some reviewers (Modi S, Lowder DM. Am Fam Physician 2006;73:72-78).

Genetic spectrum of familial hemiplegic migraine in a Danish population (Thomsen LL et al. Brain February 2007;130:346-356). A total of 147 FHM patients from 44 different families were identified. Linkage analysis of 43 families shows clear linkage to the FHM locus (FHM1) on chromosome 19, supportive linkage to the FHM2 locus, and no linkage to the FHM3 locus. Only $6(14 \%)$ of 42 FHM families have FHM mutations in the CACNA1A or ATP1A2 gene. None has mutation in the SCN1A gene. FHM is generally caused by mutations in genes other than the CACNA1A, ATP1A2 and SCN1A genes. In most large families, FHM has an autosomal dominant inheritance with perhaps more locus heterogeneity than described previously.

\title{
COENZYME Q10 DEFICIENCY AND MIGRAINE RESPONSE TO SUPPLEMENTATION
}

The prevalence of coenzyme Q10 (CoQ10) deficiency and effectiveness of CoQ10 supplements in treatment of migraine were assessed in a study at the Cincinnati Children's Hospital, OH. Total CoQ10 serum levels measured in 1550 migraine patients, age $13.3 \mathrm{H}-$ 3.5 years (range $3-22$ years), was $0.60+/-0.20 \mathrm{mcg} / \mathrm{mL}$ (range $0.21-1.77 \mathrm{mcg} / \mathrm{mL} ; 33 \%$ were below the reference range of $0.5-1.5 \mathrm{mcg} / \mathrm{mL}$ Patients with low CoQ10 levels (below 0.7 $\mathrm{mcg} / \mathrm{mL}$ ) received supplements of 1 to $3 \mathrm{mg} / \mathrm{kg}$ per day of CoQ10 in liquid gel capsule form. In 250 patients seen at follow-up (mean, 97 days), CoQ10 levels had increased to $1.20 \mathrm{H}$ $0.59 \mathrm{mcg} / \mathrm{mL}(\mathrm{P}<0.0001)$, and headache frequency improved from $19.2+/-9,8$ days per 
month to $12.5+/-10.8$ days per month $(\mathrm{P}<0.001)$. A $50 \%$ reduction in headache frequency was obtained in $46.3 \%$ patients. Headache disability measured by the PedMIDAS score improved from 47.4 to $22.8(\mathrm{P}<0.001)$, and headache disability grade improved from 2.6 (moderate) to 1.9 (mild) $(\mathrm{P}<0.001)$. (Hershey AD, Powers SW, Vockell A-LB, et al. Coenzyme Q10 deficiency and response to supplementation in pediatric and adolescent migraine. Headache February 2007;47:73-80). (Respond: Dr Andrew D Hershey, Division of Neurology, Cincinnati Children's Hospital Medical Center, 3333 Burnet Ave, Cincinnati, $\mathrm{OH} 45229)$.

COMMENT. CoQ10 deficiency may be common in pediatric and adolescent migraine, and supplementation may result in decreased headache frequency and disability. CoQ10 is included among several alternative ("natural") therapies with suggested potential effectiveness in migraine prevention. These include riboflavin, feverfew, and magnesium. A randomized controlled trial of CoQ10 ( $3 \times 110 \mathrm{mg} /$ day) compared to placebo in 42 migraine patients found CoQ10 superior for lessening attack-frequency, headache-days and days with nausea, after 3 months treatment (Sandor PS et al. Neurology 2005;64:713-715).

Modi S and Lowder DM, of ECU Brody School of Medicine, NC, reviewed published trials of medications for migraine prophylaxis (Am Fam Physician 2006;73:7278) and found sufficient evidence to recommend propanolol, timolol, amitryptyline, divalproex, sodium valproate, and topiramate as first-line migraine prevention agents. Evidence to support the use of coenzyme Q10, riboflavin, and magnesium in migraine prophylaxis is limited, and data and opinions on feverfew are mixed. The above study should prompt further investigation and trials of CoQ10 in migraine pediatric patients, over longer periods. CoQ10 and high-dose vitamin therapies in children with mitochondrial disease are found possibly effective in the short term, but ineffective in the longer term (Panetta J et al. J Inherit Metab Dis 2004;27:487-498).

\section{INFECTIOUS DISEASES}

\section{INFLUENZA A, FEBRILE SEIZURES, AND POSTICTAL PROLONGED IMPAIRMENT OF CONSCIOUSNESS}

Febrile seizure (FS) patients in a one-year period, 2003-4, during an outbreak of influenza A in the Kitakawachi area of Japan, were prospectively analyzed by researchers at Hirakata City Hospital and Osaka Medical College. Influenza patients $(n=47,22 \%)$ and noninfluenza patients $(\mathrm{n}=168)$ with FS were compared with regard to clinical features of FS. Only one patient in this period had influenza B. Influenza virus infection was confirmed by rapid antigen test and/or serologically. One or more features of complex FS were exhibited in a total of $71(33 \%)$ patients. Postictal impairment of consciousness was prolonged for more than $30 \mathrm{~min}$ (PPIC) in $28(13 \%)$ patients. None had evidence of other intracranial pathology or symptomatic seizure etiology. Associations of influenza A with complex FS (prolonged, partial, multiple seizures) and PPIC were analyzed by multiple logistic regression. PPIC occurred more often in influenza than in non-influenza patients (10/47 [21\%] vs 18/168 [11\%], $\mathrm{P}=0.057)$. The influenza $\mathrm{A}$ group was significantly older than non-influenza FS patients: $40+/-22$ vs $27+/-17$ months, $\mathrm{P}<0.001$. Influenza $A$ was independently associated with PPIC ( $\mathrm{P}=0.006)$, but not with other atypical features of the complex FS. Partial FS was 